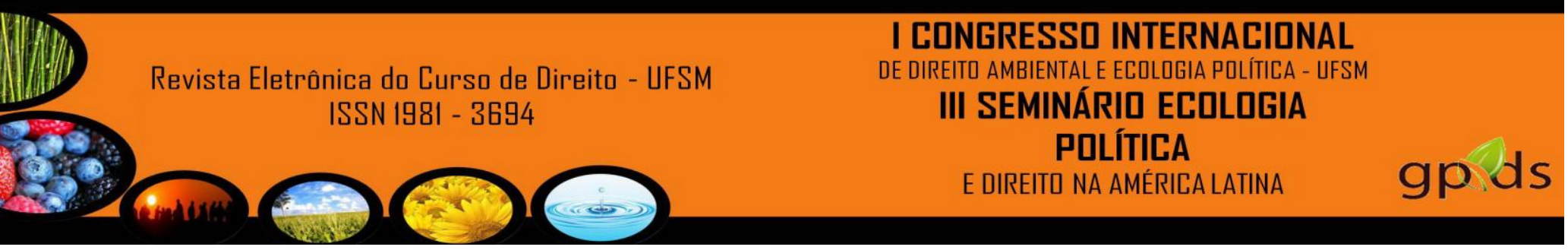

\title{
TUTELA JURÍDICA DO MEIO AMBIENTE ${ }^{1}$
}

Luiza Damião Weber $^{2}$

Maurício Fernandes da Silva ${ }^{3}$

\begin{abstract}
Resumo
A partir da necessidade de frear a estrutura social complexa e se pensar a cerca da utilização dos meios naturais e da interação do homem com a natureza. O direito serve de instrumento para ligar os vínculos e demarcar os limites entre o homem e a natureza. E é nesse palco que políticos e cientistas instituem diretrizes ao que mais tarde seria visto como o surgimento de um novo direito, comprometido com as futuras gerações, classificado como um direito fundamental de terceira dimensão, transdisciplinar e ecocêntrico. O direito ambiental propriamente dito.

Encontra-se aí o ponto de partida para a constante busca pelo equilíbrio ecológico advindo da colaboração da sociedade, economia e do próprio ambiente para se sustentar, a fim de suprir o ditame constitucional, da garantia do meio ambiente ecologicamente equilibrado e essencial à sadia qualidade de vida das presentes e futuras gerações.
\end{abstract}

Palavras-chaves: proteção, futuras gerações, direito ambiental.

\section{INTRODUÇÃO}

A busca incessante por medidas de recuperação ecológica, bem como de preservação do planeta, enfrentadas atualmente, refletem a estirpe do homem em detrimento da natureza ao longo dos anos no planeta Terra. O homem, ao viver da natureza, nem sempre teve essa visão holística dos dias de hoje, sistêmica, pelo contrário. Inclusive, Fritjof Capra define que a analise do pensamento sistêmico é "feita no contexto de um todo mais amplo", enquanto o pensamento analítico significava “isolar alguma coisa a fim de entendê-la”, (CAPRA, 1996, p. 41).

Com as inovações tecnológicas oferecidas, principalmente a partir do século XVIII, o uso e apropriação da natureza para benefício do homem começou a decair. Com a Revolução Industrial, o crescimento dos centros urbanos, os novos

\footnotetext{
${ }^{1}$ Resultado parcial da monografia intitulada "Sistema Nacional de Unidades de Conservação: aspectos jurídicos de proteção à biodiversidade do Parque Estadual do Turvo", defendido na Faculdade de Direito de Santa Maria - FADISMA, vinculado à Linha de Pesquisa "Meio Ambiente e transnacionalização do Direito".

${ }^{2}$ Autora, bacharel em direito pela Faculdade de Direito de Santa Maria (FADISMA). E-mail:

Luiza.wbr@hotmail.com

${ }^{3}$ Orientador, graduado em Direito pela Ulbra, especialista em Direito Ambiental pela UFPEL, advogado, professor da área de Direito Ambiental na Faculdade de Direito de Santa Maria. Advogado. E-mail: mauricio.silva@fadisma.com.br
} 
consumos através da apropriação dos recursos naturais aumentaram os problemas ambientais, advindos da inversão de paradigmas, ocasionaram o surgimento da sociedade de risco da época pós-moderna. Com isso, corrobora-se a percepção da necessidade de modificação do direito e das regras de convivência.

Com efeito, diante da exposição relativa a situação do meio ambiente, é imprescindível compreender os motivos pelos quais o meio deve ser preservado. Defronte ao que está escrito no Livro Vermelho da fauna ameaçada de extinção no Rio Grande do Sul, é possível visualizar a substituição da visão antropocêntrica, unitária, na qual o homem é o centro do mundo, pela visão ecológica, baseada na preservação ${ }^{4}$ do meio: "De fato, grande parte da nossa existência depende do uso direto ou indireto da biodiversidade, sob a forma de alimentos, fonte de medicamentos e composto químicos, materiais diversos, produtos essenciais, etc. todas as espécies animais e vegetais também são componentes importantes dos ecossistemas". (FONTANA; BENCKE, 2003, p. 16)

Por sua vez, esses sistemas ecológicos prestam-nos inúmeros serviços, que raramente são conhecidos ou valorados economicamente. Esses serviços essenciais dos ecossistemas naturais e da biodiversidade a eles associada incluem a polinização, a reciclagem de nutrientes, a fixação de nitrogênio no solo, a regulação do clima, a dispersão de sementes, a purificação da água, o controle biológico de populações, o lazer, etc. (FONTANA; BENCKE, 2003)

Somente depois de intenso trabalho de "conscientização pública",5, perpetrada por diversos grupos de cientistas e ambientalistas, que alguns países se despertaram para a necessidade de criar mecanismos hábeis a proteger os seus ecossistemas. O Brasil, a partir do amparo constitucional, que reconheceu o meio ambiente como um direito fundamental, instituiu leis que garantissem esse estado do ambiente sadio e equilibrado, requerido pela Constituição vigente, conforme disposto a seguir.

\footnotetext{
${ }^{4}$ Ação de proteger, contra a destruição e qualquer forma de dano ou degradação, um ecossistema, uma área geográfica definida ou espécies animais e vegetais ameaçadas de extinção, adotando-se as medidas preventivas legalmente necessárias e as medidas de vigilância adequadas, (MILARÉ, 2009, p.1330).

5 "Resultado de tal conscientização e como reflexo das exigências da opinião pública internacional, em 1972, a ONU convocaria a conferência em Estocolmo, tida como um dos marcos do Direito Internacional do Meio Ambiente, especialmente dedicada ao Meio Ambiente Humano.
} 


de determinadas atividades, com a complexidade das reações ambientais de danos presentes ou futuros e com o controle e a regulamentação das inovações tecnológicas", (CARVALHO, 2008. p. 46).

Seguindo essa linha de entendimento, o direito ao meio ambiente estabelecido no rol das gerações de direitos fundamentais, como um direito fundamental de terceira geração, o direito ambiental, é fundamentado pelos direitos de fraternidade e de solidariedade, e ligado a um profundo humanismo e ao ideal de uma sociedade mais justa e solidária. Como uma espécie de resposta ao fenômeno de degradação sofrido pelos direitos e liberdades fundamentais. $\mathrm{O}$ direito ao meio ambiente refere-se ao direito do Estado intervir nas relações com o ambiente para protegê-lo e defendê-lo.

Dessa forma há uma especial relevância do direito ao meio ambiente e à qualidade de vida. Inclusive, é cabível o comentário de José Joaquim Gomes Canotilho a cerca do tema: "Com a superação do Estado Liberal de Direito ${ }^{6}$ em sua forma clássica e com o advento do Estado do bem-estar social ${ }^{7}$, houve o redimensionamento da importância dos direitos fundamentais, enfatizando sua concepção multifuncional. Superou-se, assim, a noção de que os direitos fundamentais serviriam unicamente à defesa do individuo contra o Estado; reconhecendo-se que os direitos fundamentais, alem disso, servem à proteção e à materialidade de bens considerados importantes para a comunidade", (CANOTILHO, 2007. p. 192 e 193).

Nesse viés, importante compreender que os interesses defendidos pelo Direito ambiental $^{8}$ não pertencem à categoria do Direito Público, nem do Direito Privado. Conforme dita o doutrinador Luis Paulo Sirvinkas, esse ramo do direito: "cuida sim, de interesse pertencente a cada um e, ao mesmo tempo, a todos", (SIRVINSKAS,

\footnotetext{
${ }^{6}$ O Estado Liberal do Direito se consolidou a partir das Revoluções Burguesas do século XVIII, caracterizadas pó defender as maiores cotas possíveis de liberdade do individuo diante do estado, modelo social este que substituiu o antigo regime, (CRUZ, 2001 p. 89 apud CANOTILHO; LEITE, 2007, p.192).

${ }^{7}$ O Estado de bem-estar é o produto da reforma do modelo clássico de Estado Liberal que pretende superar as crises de legitimidade que este possa sofrer, sem abandonar sua estrutura jurídico-politica. Caracteriza-se pela união da tradicional garantia das liberdades individuais com o reconhecimento, como direitos coletivos, de certos serviços sociais que o Estado providencia aos cidadãos, de modo a propiciar iguais oportunidades a todos, (Ibid., p.207 apud CANOTILHO; LEITE, 2007, p.192).

8 "É a ciência jurídica que estuda, analisa e discute as questões e os problemas ambientais e sua relação com o ser humano, tendo por finalidade a proteção do meio ambiente e a melhoria das condições de vida no planeta", (SIRVINSKAS, 2001 p. 35).
} 
III SEMINÁRII ECDLOGIA

POLÍTICA

2001. p. 35). Denominado como interesses transindividuais, ou difusos, o direito ambiental está situado numa zona intermediária, entre o público e o privado.

Verifica-se inclusive, que além de um direito difuso, o direito ambiental é transdiciplinar, conforme o entendimento do Professor Michel Prieur, da Universidade de Limoges, França, e Diretor do Centro de Direito Ambiental, de forma apropriada acentua: "Na medida em que o ambiente é a expressão de uma visão global das intenções e das relações dos seres vivos entre eles e com seu meio, não é surpreendente que o Direito do Ambiente seja um Direito de caráter horizontal, que recubra os diferentes ramos clássicos do Direito (Direito Civil, Direito Administrativo, Direito Penal, Direito Internacional), e um Direito de interações, que se encontra disperso nas várias regulamentações. Mais do que um novo ramo do Direito com seu próprio corpo de regras, o Direito do Ambiente tende a penetrar todos os sistema jurídicos existentes para orientar num sentido ambientalista", (apud MACHADO, 2010. p. 54).

Nota-se até aqui, que o reconhecimento à tutela jurídica do direito ao ambiente, é resultado de uma grande evolução do reconhecimento dos direitos fundamentais e da organização do Estado juntamente com a coletividade, exercendo um comportamento não nocivo ao meio ambiente ecologicamente equilibrado.

Diante disso, importante se faz analisarmos essa tutela ambiental disposta nas constituições em vigor e as que a antecederam, como também, compreender de que forma o direito ambiental foi efetivado pelo ordenamento jurídico vigente, importando para tanto, o conhecimento do meio ambiente como um bem de uso comum do povo e essencial à sadia qualidade de vida.

\section{1.2- A Constitucionalização do Meio Ambiente}

A partir do movimento ambientalista ${ }^{9}$ na década de 70, as preocupações voltaram-se efetivamente para o meio ambiente. Incorporando novas reivindicações às

\footnotetext{
${ }^{9} \mathrm{O}$ movimento ambientalista foi considerado um movimento social fruto de um período histórico que exerce pressão nos órgãos oficiais e, também inserido neles, faz com que os Estados tomem medidas para defesa de um meio ambiente saudável, (CASTELS, 1999).
} 


III SEMINÁRII ECDLOGIA

PDLÍTICA

E DIREITD NA AMÉRICA LATINA

patrimônio ambiental, tanto natural quanto cultural e por finalidade a incolumidade da vida em geral, tanto a presente como a futura, (MARCHESAN; STEIGLEDER; CAPPELLI, 2005. p. 34).

Por sua vez, na vigente Constituição da República Federativa do Brasil publicada em 5 de outubro de 1988, o legislador reservou o Capítulo VI, do Título VIII, para as questões do meio ambiente. Assegurou no artigo 225, o meio ambiente sadio e ecologicamente equilibrado, como um direito de todos: "Todos têm direito ao meio ambiente ecologicamente equilibrado, bem como de uso comum de povo e essencial à sadia qualidade de vida, impondo-se ao Poder Publico e à coletividade o dever de defendê-lo e preservá-lo para às presentes e futuras gerações”, (BRASIL, 2007. p. 157).

Assegurou também, a proteção da fauna e flora, contra práticas que coloquem em risco sua função ecológica, provoquem extinção de espécies ou submetam os animais à crueldade.

Esse dispositivo constitucional reconheceu o direito a um meio ambiente ecologicamente equilibrado como direito fundamental da pessoa humana. Mesmo que o constituinte tenha optado por inserir o direito ambiental no título da ordem social, este é clausula pétrea e sujeito a aplicabilidade direta.

Ademais, ao instituir o meio ambiente como um bem jurídico autônomo, traduz verdadeiros interesses difusos, que não podem ser dispostos, nem pelo individuo, nem pelo Estado. Podendo ser defendido, não somente pelo Ministério Publico, como também por todos que desejarem fazê-lo, por meio de Ações populares, assegurada no inciso LXXIII do artigo $5^{\circ}$ da $\mathrm{CF} / 88^{11}$ e ações civis publicas, disciplinada pela Lei $\mathrm{n}$. 7.347 , de 24 de julho de 1985 , inciso I, artigo $1^{{ }^{12}}$.

\footnotetext{
${ }^{11}$ Art. $5^{\circ} \mathrm{CF} / 88$ - Todos são iguais perante a lei, sem distinção de qualquer natureza, garantindo-se aos brasileiros e aos estrangeiros residentes no País a inviolabilidade do direito à vida, à liberdade, à igualdade, à segurança e à propriedade, nos termos seguintes:

LXXIII - qualquer cidadão é parte legítima para propor ação popular que vise a anular ato lesivo ao patrimônio público ou de entidade de que o Estado participe, à moralidade administrativa, ao meio ambiente e ao patrimônio histórico e cultural, ficando o autor, salvo comprovada má-fé, isento de custas judiciais e do ônus da sucumbência;

${ }^{12}$ Art. $1^{\circ}$ - Regem-se pelas disposições desta Lei, sem prejuízo da ação popular, as ações de responsabilidade por danos morais e patrimoniais causados:

1 - ao meio-ambiente;
} 


\section{CONSIDERAÇÕES FINAIS:}

É certo que ao longo do tempo a prática humana degradou a biodiversidade utilizando, reduzindo, poluindo, explorando o meio ambiente. Entendese que muitos desses danos que lhe foram causados não podem mais ser recuperados. Entretanto, sabe-se também que é da natureza que provem o desenvolvimento humano, toda atividade humana desenvolve-se em vários ecossistemas, sejam eles equilibrado ou não, tendo, portanto, suas atividades econômicas a sua razão de ser, a partir da existência dos recursos naturais.

Diante desse constante processo de modificações, de mudança de paradigmas, de crises e riscos, já não restam dúvidas sobre a necessidade de preservação e conservação do meio ambiente. Tanto que, diante dessa situação, emergiu um novo ramo do direito, o Direito Ambiental, que veio a tutelar o meio ambiente como um bem de todos para que possa ser efetivamente garantido.

Na visão holística atual, sabe-se que a prevenção é o instrumento que garantirá a preservação do imprescindível meio ambiente. Inclusive porque o desenvolvimento sustentável é considerado um princípio fundamental pela Constituição Federal, e é a partir daí que se instrumentaliza o amparo necessário para garantir e assegurar os direitos fundamentais, no caso, o direito ambiental. De forma a cumprir com o descrito no artigo 225, que dispõe ser direito de todos, o meio ambiente ecologicamente sadio e equilibrado. O Poder Público instituiu inclusive que é dever não só do Poder Público, como de toda coletividade, defendê-lo e preservá-lo.

A partir deste estudo ficou evidente que determinados danos no ambiente atual são irreparáveis e impossíveis de se medir consequências. O dever do direito seria como dar um alerta de calamidade a sociedade atual, mas não somente para essas pessoas que vivem no mundo hoje, mas também para a responsabilidade que elas tem com o ambiente que deixarão as próximas gerações. É a partir de uma nova formação de vínculos e limites entre o homem e o meio ambiente que será possível solidificar um desenvolvimento que sustente a nossa biodiversidade para o futuro. 


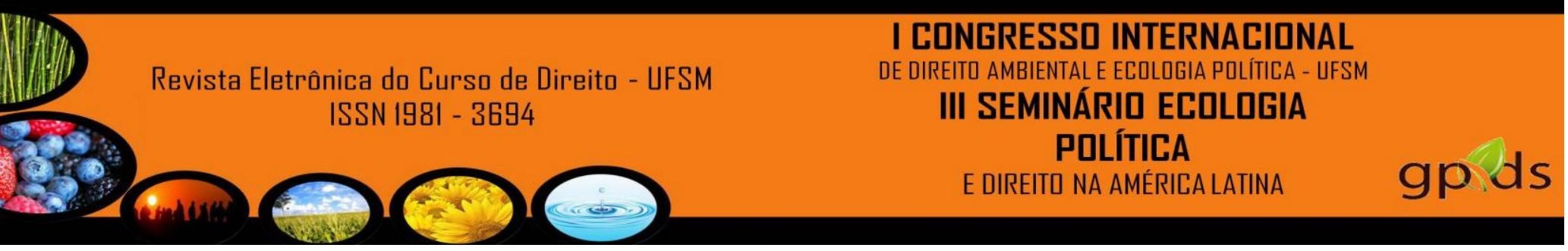

MACHADO, Paulo Affonso Leme. Direito Ambiental Brasileiro. 18 ed. ver., ampl. e atual. São Paulo: Malheiros editores Ltda, 2010.

MARCHESAN, Ana Maria Moreira; STEIGLEDER, Annelise Monteiro; CAPPELLI, Sílvia. Direito ambiental. 2. ed. Porto Alegre: Editora Verbo Jurídico, 2005

MILARÉ, Édis. Direito do ambiente: a gestão ambiental em foco. 6.ed. rev. atual. e ampl. São Paulo: Revista dos Tribunais, 2009.

OST, François. A natureza à margem da lei: a ecologia à prova do direito. Direito $\mathrm{e}$ direitos do homem. 2004.

SACHS, Ignacy. Estratégias de transposição para o século XXI: desenvolvimento e meio ambiente. São Paulo: Fundap/Studio Nobel, 1993

SÉGUIN, Elida. CARRERA, Francisco. Planeta Terra: uma abordagem de direito ambiental. 2. ed. rev. Rio de Janeiro: Lumen Juri, 2001.

SIRVINSKAS, Luís Paulo, Manual de direito ambiental. 6. ed. rev. ampl. e atual. São Paulo: Saraiva, 2001.

SILVA, José Afonso da. Direito Ambiental Constitucional. 6 ed. São Paulo: Malheiros, 2007. 